\title{
A Study on Interiorization of the Elements of External Space in Contemporary Architecture's Interior
}

\author{
Kwang-ho Kim*1 and In-seok Koh ${ }^{2}$ \\ ${ }^{1}$ Assistant Professor, School of Architecture, Inha University, Korea \\ ${ }^{2}$ Graduate Student, School of Architecture, Inha University, Korea
}

\begin{abstract}
This study aims at analyzing the methodology of metaphorical and analogical design thinking in terms of interiorization of the elements of the exterior (urban and landscape) in contemporary architecture's interior. The concept of interiorization of the external elements was studied as follows:

First, in an approach focused on system, by the mode of metaphorical transference, substantial fluid energy of natural ecology in the exterior is transferred into the interior.

The second is an approach focused on program, and it is a mode of analogy in which an event can be made. It can be from an indeterminate program and structure of plate of the interior analogized by various programs and infrastructure of the exterior.

The third is an approach focused on image. It introduces the elements of exterior prospect into the interior metaphorically and analogically, and appeals directly to aesthetic feeling through emotional expressions.
\end{abstract}

Keywords: analogy; metaphor; landscape; figuring the ground

\section{Prologue}

\subsection{Background and Purpose}

From the perspective of architectural history, the attitudes and methods which establish the relationship between interior space and exterior space clearly reflect the philosophy of an architect, and they are considered significant as elements of interpretation of contrastive characteristics of architecture such as functional and aesthetic aspects. As the landscape keeps more direct continuity with the exterior and in turn is less constrained by functional and structural conditions than the interior, it has been the main object by which we experimented physical and aesthetic influences in various ways that human beings experienced in nature. While the public aspect of the exterior is usually stressed in landscape design, the private aspect of the exterior is stressed in architecture design.

In modern architecture, various scales of the public interior spaces began to appear rapidly and are merely characterized by its huge volume and intense illumination or by planting a few trees.

Since the public interior space as such can induce a public experience similar to that of the exterior of landscape design, it is expected to have a positive effect on human psychology. Considering the fact that most

*Contact Author: Kwang-ho Kim, Assistant Professor, School of Architecture, Inha University, \#253 Yonghyun-dong, Nam$\mathrm{ku}$, Incheon, 402-751 Korea

Tel: +82-032-860-7580 Fax: +82-032-866-4624

e-mail: 200022@inha.ac.kr

(Received November 7, 2002 ; accepted February 28, 2003 ) of our time is spent indoors, qualitative improvement of the interior experience is possible by analogical or metaphoric interpretation of the elements of the exterior space.

\subsection{Methodology and Scope of the study}

This study will consider modern architecture which was built through thinking process of metaphor and analogy in applying the elements of the exterior into the interior. This mode of metaphor and analogy has been appropriated variously and objectively in 20th century architecture, and it is composed by three following attitudes of approach.

The first one is an approach focused on system, which is a mode of metaphorical transference. The fluid energy of natural ecology, that is substantiality of the exterior space, can be transferred into the interior.

The second is an approach focused on program. It is a mode of analogy in which an event can be made from an indeterminate program and structure of plate of the interior analogized by various programs and infrastructure of the exterior.

The third, an approach focused on image introduces the elements of outside prospect into the interior metaphorically and analogically and appeals directly to our aesthetic feeling through emotional expressions.

The idea of these 3 attitudes is correctional correspondence to the structure, the function and the beauty that have been center of the constructional debate so far in the modern architecture.

This thesis will define the concepts of system, 
program, and image, and search for the concrete introduction of the elements of the exterior into the interior and furthermore provide the theoretical background of the correlation between them.

\section{Interiorization of the Elements of the Exterior} - Figuring the Ground

'Landscape' is a compound of the two words, 'land' and 'scape'. Landscape changes according to the topography or the historical influence of human beings on land. Therefore, landscape reflects the movement of contemporary people and social or natural system. Compared to the ceaselessly changing and moving landscape, architectural material is static and limited. The main theme of the recent non-linear architecture deals with combination of them. Contrary to the typical role of floor which has been considered as ground rather than wall in architectural design, land itself creates dynamic images and becomes figuring in this point of view.

By applying such features of the exterior into the interior of architecture and figuring the ground which cannot be confined in the constraint of the principle of Ground \& Figure whose design object is centered on figure rather than ground, a complementary approach in design methodology can be made possible which includes not only intuitional but also empirical aspects within the confinement of generally rational and transcendental limits.

'Analogy' is one of the ways of 'Figuring the Ground' which makes it possible to do that for the purpose of introducing the exterior scenery into the interior by transferring the original meaning from logical or emotional aspect, and this analogy has an intellectual characteristic in that this comes from logical inference or prescription, that is, there is a possibility of another identifiable characteristic when individual features share common denominators.

On the other hand, 'metaphor' is emotional in that metaphor as a figurative expression substitutes tenor, and the meaning is transferred in rhetorical aspect. That is, while 'analogy' is syntactic transference because the transferred content depends on the structural relationship by proportion, 'metaphor' is semantic transference because it transfers the meaning and concepts. ${ }^{1}$ Analogy and metaphor are the concepts of transference between two elements of similar properties. Analogy on the one hand is usually used to provide with unknown solutions to familiar problems by new interpretations, and on the other hand metaphor is adopted to connect conflicting concepts from emotional perspective in order to inspire creative human wills.

Generally, the principle of 'figure \& ground' was supported by the relationship of confronting dichotomy between architecture and land which are severed by wall. Recently, however, the fundamental figuring of the ground has been tried such as metaphor of energy of natural ecology, analogy or introduction of external programs including various behaviors, or mode of metaphor transferring contemplative images from exterior perspective. As follows, this thesis will consider how the process of internalization of the elements of the exterior space transferred by analogy or metaphor embodies the concept of 'figuring the ground' when it is applied to each of three modes of approach.

\section{Mode of approach to the interiorization focused on 'System' \\ 3.1 Characteristic of the Concept of System in Contemporary Architecture}

System, which is the concept of relationship between specific assemblages, means forming a multi-layered hierarchical structure while having various qualitative relations on the ground of unified order of various components.

From modern science's viewpoints, the traditional idea of system is a linear causal relation, which is reductive, mechanical, and vertical hierarchy. This linear system, however, follows the principle of reorganization that considers only quantitative addition while ignoring qualitative effects of interaction between the elements of the system. In other words, the whole phenomena of the universe including from lifeless inorganic material such as water to a nomad have relation to one another ceaselessly exchanging information and energy in system.

This linear model ignoring the qualitative change in system had not been reconsidered until new contemporary physics such as chaos theory supported its reconsideration, and suggested its displacement with non-linear system. That is, now we, who are conscious of Gaia system as being Holon, take a interest in the organic system, and start to reestablish our relationship severed from nature. ${ }^{2}$

Contrary to the past researches of this intellectual paradigm focused on static forms which had been controlled by the causal relationship, now the discussion about dynamic changes in themselves are active. The organic system is a self-operating organic system, and while keeping its structure of unified order, it at once controls and transforms itself. This can be possible only through the transformation of evolving forms and growth adapting itself to chaotic surroundings and keeping its inner order.

\subsection{Development of Digital Media and Metaphor of Organic System}

The philosophy of an architect as a metaphor of cosmology is applied to a building, and in turn it is an important clue of establishing the relationship between architecture and surroundings. This can be confirmed by following examples. The sphere form architecture of Louis Boullee of late $18^{\text {th }}$ century is a metaphor of the linear relationship, and the contemporary organic system is the antithetical concept of non-linear relationship.

As we have considered, this organic system possesses 
dynamic state ceaselessly interchanging energy and information, and the inner characteristic of asymmetrical but stable and unified order at the same time. As seen, the wholeness of double order, that is dynamic and static simultaneously, can be transferred into liquefied metastability by metaphor. This stems from the fact that the liquefied model means both the dynamic generation through phase shift and differentiated inner order at the same time. ${ }^{3}$ That is, meta-stability means ability to adapt flexibly to the outer surroundings of organic energy, and to exchange and transform littered information in the inside.

Here organic energy ceaselessly controlling and renovating itself, and digital media reorganizing and shifting information through liberating network can find a common denominator, that is fluidity. Fluidity, a wellknown characteristic of information technology, is not fixed in a specific place as bit unit information but connects with other users or arbitrary information through web-like network. This information is reorganized as organic system and shifts to a different phase, and thus brings up dynamic change in the whole system.

Digital architecture powered by new digital technology confirms that the meaning of organic system was transferred to architecture by its metaphor. The characteristics of digital architecture which introduces surroundings into the interior of the building can be classified according to the following three aspects.

First, architecture of the past means the severance from the outside, and defines the meanings of the inside and the outside. However, as the organic skin of the nerve system receives inchoate information of the outside, the skin of digital architecture, which is transparently open, exchanges information openly within the minimum limits.

Second, it introduces meta-stability, which is metaphor model of organic energy, into the interior. In this introduction, breaking from the static characteristic of architecture, it can be metaphor of possibility of ceaseless exchange of information and energy by endowing to the interior the meanings of growth, evolution, selfrenovation, and control.

Third, as the interior of organic system exchanges flexibly information and energy with its inner unified order, a line of flow in the interior of architecture exists flexibly as the ceaseless flow like the interior of organic system.

The application of the idea of symbolizing this organic system often appears in modern constructions in two tendencies. The first is to introduce the fluid model into a building of box shape whose skin is open with light transparency, and this is applied in the context of city. The second is the intaglio technique to penetrate into the trace of land in direct juxtaposition by introducing the fluid model into the very skin of a building, and this is usually used when the surrounding context is in natural state.

\begin{tabular}{c|c|c|c}
\hline & $\begin{array}{c}\text { organic system } \\
\text { (object of } \\
\text { transference) }\end{array}$ & $\begin{array}{c}\text { digital } \\
\text { technology } \\
\text { (method of } \\
\text { transference) }\end{array}$ & $\begin{array}{c}\text { application in } \\
\text { architecture } \\
\text { (result of } \\
\text { transference) }\end{array}$ \\
\hline $\begin{array}{c}\text { concept } \\
\text { of } \\
\text { object }\end{array}$ & $\begin{array}{c}\text { exchange of } \\
\text { information and } \\
\text { energy with outer } \\
\text { surrounding }\end{array}$ & $\begin{array}{c}\text { information } \\
\text { exchange and } \\
\text { change by } \\
\text { web-like network }\end{array}$ & $\begin{array}{c}\text { information } \\
\text { exchange by } \\
\text { transparency or } \\
\text { lightness of skin of } \\
\text { a building }\end{array}$ \\
\hline $\begin{array}{c}\text { Form } \\
\text { of } \\
\text { object }\end{array}$ & $\begin{array}{c}\text { Energy of fluid } \\
\text { ecology }\end{array}$ & $\begin{array}{c}\text { fluidity of } \\
\text { ghase by digital } \\
\text { matrix }\end{array}$ & $\begin{array}{c}\text { skin structure of } \\
\text { fluid building or } \\
\text { liquid interior } \\
\text { structure }\end{array}$ \\
\hline
\end{tabular}

Table 1. Process of Metaphor in Ecological System

The important point in this place is that, when introducing the outside scenery into the interior transferred by metaphor through digital technology, figuring the ground can be experienced in the meaning of cognitive psychology. This can be possible because the concept of organic system of nature, when it discovers the same "fluidity" as digital system possesses, can find the possibility of transference of meaning. It is significant in that the old antagonistic relations between men and nature can be harmonized through such a coupling device as digital high technology.

\subsection{Case Study}

- Sendai Mediatheque, Sendai, 1997, Toyo Ito

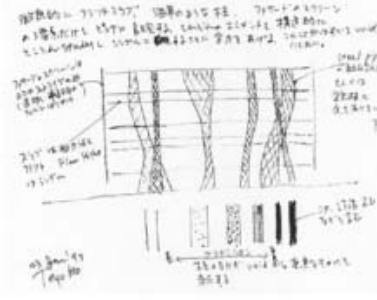

Fig. 1. Ito's Image Sketch -seawead-like columns-

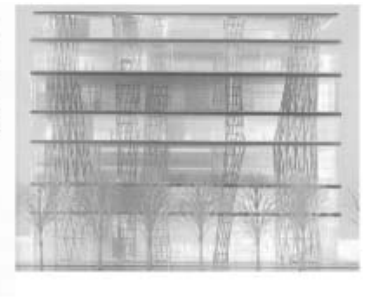

Fig. 2.Sendai Mediatheque Model
As Ito mentioned the fluidity that appears in the universal space of Mies' Barcelona pavilion, he defined the experience in that place as the flow in density like underwater. In other words, the transparency of Barcelona pavilion is the experience of translucency like underwater, and this can be interpreted as the dense combination of the inside and the outside. While he paid attention to the light superficial relationship between the inside and the outside, he applied the fluid space, which instantly corresponds to the soft body, to a structure. The fluid space that embrace the softness of humans like this makes each other sublate the relationship of hierachy, activate the interchange between the object and the subject, thereby corresponding to the relative perspective of the decentralized society.

Sendai mediatheque, as Ito said, revives the experience of the translucency like underwater, and the sendai 
mediatheque, that correspond to the soft human body, is the public facility integrated into the library and the art museum and consists of 13 glass tubes and 7 bottom boards. 13 glass tubes are the metaphor image of underwater plants, and as we can see from the phrase 'seawead-like columns' in his early sketch the fluid glass tube symbolizes the underwater living bodies and the wiring tubes inside it symbolizes the neural structure of the organisms. The underwater organisms are free form gravity compared to the land animals and appear to be more like the essential form of the organisms, that is, the form of strong fluidity that represents the movement itself.

The inner space reminds us of the natural forest of underwater and the inside that has no columns and walls only prescribes the place. This applies different types and sizes of glass tubes, various arrangement techniques, difference in lighting types, height difference in various layers, etc., escapes from the grid space of walls and beams, and constructs a flexible artificial natural space. And the outer cover is open because of the transparency of the glass, making the distinction of the inner and the outer spaces vaguely turbid. This transparent wall structure is the connective element that transmits the information between the nature and the structure and it limits the outer information to the minimum. Here the structure that was in indifferent relationship with the surrounding environment prepares a harmonizing proviso, and we the isolated are faced with the phase that is connected with the outer environment.

\section{Mode of approach to Interiorization of the External elements focused on 'Program'}

\subsection{Characteristics of the Event Program in Contemporary Architecture}

In the construction of architectural space, as seen in Le Corbusier's concept of "Architectural Promenade," a resident is led by sequence experienced in various objects and ceaseless line of flow intersected by an architect's intention. The fact that the architect has elitist authority and can control the human behaviors comes from the traditional idea that human beings can be placed under

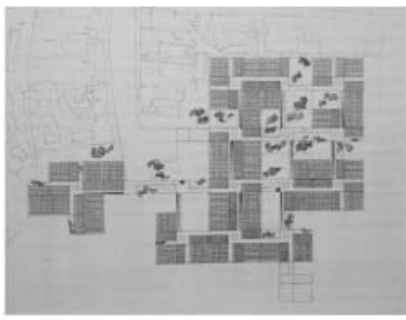

Fig. 3. Venice Hospital Project control by programs determinated rationally. Therefore, Le Corbusier took his chief interest in the design programmed systematically, and emphasized on the static i mage dividing distinctively the exterior and the interior.

The Venice hospital confirms Le Corbusier's idea of determinate program. The organic characteristic of the canal in Venice, the main network of transportation, which has cursive, successive movement, and the discontinuous grid pattern of the building are in striking contrast.
This work was disputed by Team 10, who led postmodernism movement, for the reason that its design wanted spatiality. However, by applying the rational, mathematical building transformed form the organic city, the building of static atmosphere contrasts peculiarly with dynamic surrounding of the city in scale, directions, and spatial rhythm.

However, in this de-centered and plural society, now it is difficult not only even to predict human behaviors but also for a architect to control gigantic buildings and the public space of them by his individual authority. Accordingly, the concern of contemporary program is focused on 'indeterminate program,' that is, the concept of event. Event is a space concept which has appeared against the background of post-structuralism whose discourses will subvert the concepts of the past only seeking ideal homogeneity, and sanction difference and unstability.

Rem Koolhaas is a representative architect who suggests a new alternative of contemporary city and architecture by way of analogy wherein outer programs signifying various unpredictable behaviors can be transferred into the interior. He claims "Indeterminacy of program" in order to prevent human behaviors from being determined by a single program of an architect or a city designer. It is his assertion that there needs to be autonomy which architects should admit because of the presence of unpredictable territory in program and human behaviors.

Any unpredictable human behavior can be activated when program made by analogy of city structure of the exterior is introduced into the interior. His architectural strategy is to introduce outer chaos into the interior within minimum limits by analogy. From such a strategy, the concept of architectural order accommodates indeterminate programs(event programs) of accidental happenings, extrinsic nature within determinate programs(event programs) such as infrastructure, grid, and band. His middle position as such is called 'Chaosmos,' a compound of cosmos and chaos. This neologism signifies accommodating the external chaos within minimum limits of order. Through reciprocal intervention caused by this accommodation of chaos, boundaries are abolished, and fresh catalysts are formed to provide unimaginable surprises by superimposition of accidental and heterogeneous programs such as collage.

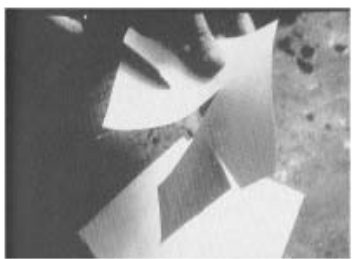

Fig. 4. The Plate Structure Study(1)

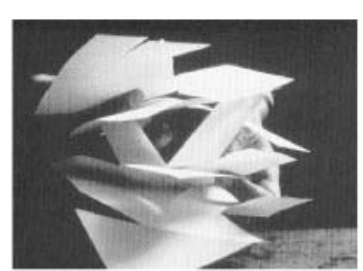

Fig. 5. The Plate Structure Study(2) 


\subsection{Analogy of Infrastructure and Structure of Plate}

Here determinate program and indeterminate program are constituted into a single successive plate by ceaselessly flowing line and the flow of heterogeneous program. The plate structure transferred from Le Corbusier's ramp by analogy is spreading with contemporary non-linear phenomenon around Holland architecture (Rem Koolhaas, MVRDV, and Ben Van Berkel). Rhizome' model suggested by Deleuze in 'Mille Plateaux' means non-hierarchical, successive, and plural flows breaking from the central power like the architecture of internet. In contemporary architecture, Rhizome concept, when applied to a section model of structure of plate, takes spatiality, and it is characterized by intersection of de-centered, heterogeneous, and plural lines, and by a possibility of interconnection with every dot blurring boundaries. This model, when applied to architecture, makes the structure of floor plate which can make boundaries vague, share and connect with anything, and accommodate successive flow of space.

This structure, as claims Rem Koolhaas, is a space within which lines of flow for accommodation of the congestion of culture similar to an aggrandized independent city can be held. The successive flow of people becomes infrastructure which can provide a whole building with vitality. That is, the structure of floor plate can be considered as another meaning of infrastructure transferred by analogy from the previous infrastructure such as roads, railroads, subway rail in a city.

\subsection{Case Study}

- Library of Jussieu University, Paris, 1993, Rem Koolhaas

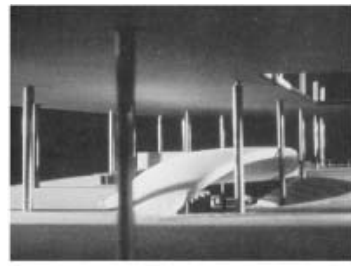

Fig. 6. Jussieu University Library(1)

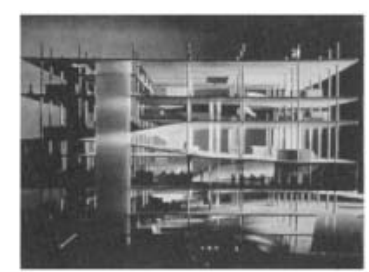

Fig. 7. Jussieu University Library(2)
"Instead of simply stacking the floors on top of one another, sections of each are manipulated to connect with those above and below - creating a vertical, intensified landscape - and are then 'urbanized,' almost like a city." As Rem Koolhaas says above, the successive line transferred from the infrastructure of city connects determinate programs with indeterminate programs, and induces various dynamic human behaviors. Event program chooses park, cafe, and, store transferred from program of city by analogy as catalyst for activator of space by introducing them into the interior.

Here, the floor plate of strong public character becomes social infrastructure inducing meeting of various events, and integrates hierarchy in the ceaseless flow.

\begin{tabular}{|c|c|c|c|}
\hline problem & $\begin{array}{c}\text { City } \\
\text { (model of } \\
\text { transference) }\end{array}$ & $\begin{array}{l}\text { Architecture } \\
\text { (object of } \\
\text { transference) }\end{array}$ & solution \\
\hline $\begin{array}{l}\text { 'Bigness' } \\
\text { in } \\
\text { contemp }\end{array}$ & $\begin{array}{c}\text { Unpredictable } \\
\text { human } \\
\text { behaviors }\end{array}$ & event program & $\begin{array}{c}\text { confirmation of } \\
\text { autonomy of plural } \\
\text { society and } \\
\text { stimulative catalyst of } \\
\text { space } \\
\end{array}$ \\
\hline $\begin{array}{l}\text {-orary } \\
\text { architect } \\
\text {-ure }\end{array}$ & $\begin{array}{c}\text { Infra-structure } \\
\text { of city }\end{array}$ & $\begin{array}{c}\text { structure of floor } \\
\text { plate }\end{array}$ & $\begin{array}{l}\text { provide the interior of } \\
\text { aggrandized building } \\
\text { with infrastructure }\end{array}$ \\
\hline
\end{tabular}

Table 2. Process of Transference by Analogy from Human Behaviors in City and Infra-structure to the Interior

\section{Mode of Approach to Interiorization of the External Elements Focused on 'Image' \\ 5.1 Characteristics of Image Concept}

Image immanent in architect's mind as subjective state of psychology and its expression is considered as the concept which lays stress on irrational emotion and intuition while surmounting the frame of rational thought.

For architects, the exterior, namely extrinsic phenomenon, is transformed into intrinsic, passive image through perception, and it in turn is transformed into image of active concept for creative extrinsic behavior through judgment of emotion and reason.

The ways of accommodation in creating passive images vary infinitely according to the individual subjective frame of experience, and the intuitional inspiration in creating active image which is beyond explication, has been frequently used for more progressive environment of architecture.

Because the concepts of general phenomena concerned with architectural aesthetics such as form, space, and place are integrated in image level, they can be communicated through intuitional vocabulary of architecture though not completed in concrete verbal form. Metaphor and analogy make it convenient to transform passive images into active images, and can transform free and various experiences of the exterior into architectural space for further application.

In this mode of approach centered on image, introduction of aspects of event and various behaviors related with the concept of program in the exterior is rarely found, and nevertheless it seeks intimacy by inducing contemplative emotions easily experienced in the exterior through more liberating metaphor and analogy.

'Aesthetic aloofness' of Kant, the concept related with contemplation, had been challenged by the spirit of behavioral experimentation of 20th avant-garde arts since its establishment, and suffered the new changes. 'Architecture of organic expressionism' which appeared from early 20 th century, is a representative trend which 
shows the application of this aesthetic disinterestedness transformed and adapted to contemporary situation. Organic architecture which can easily be transferred from the structure of nature by analogy is categorized into two. One is the category of Frank Lloyd Wright focused on geometric construction, and the other is that of Hans Scharoun, Hugo Häring, and so on centered on free form construction. In transferring solid elements from nature by metaphor and analogy one contrasts strikingly with the other in case of form, but they share common points in characteristics of expressive image transferring elements of void from the exterior by metaphor and analogy.

\subsection{Concept of Image in Modern Architecture}

- Guggenheim Museum, New York, USA, 1956, Frank Lloyd Wright

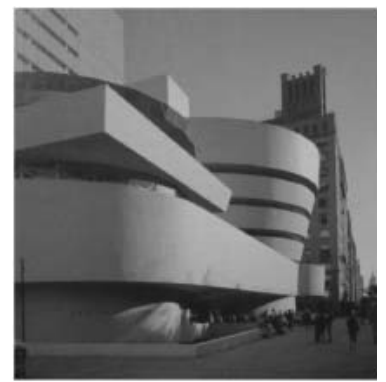

Fig. 8. Exterior of Guggenheim Museum

This museum in which Wright's organic form contrasts with the rational pattern of Manhattan in New York is known for its spiral lamps expressing powerfully the successive vertical and horizontal line of visitors. Validity of form has been disputed in the context of city. The successive movement of the spiral lamps inducing the experience of climbing a mountain and expressing the exterior contrasts with the road pattern of discontinuous grid network in Manhattan.

In the aspect of image, this contrast forms dynamic visual sequence which gives feeling of mental liberation to its visitors moving from the space of city into the interior. Its scale and changes of light seeks mental liberation by movement from the space of dark entrance compressed to the level of low ceiling to the space of central bright void.

Wright, as an advocate of organic architecture, seemed to take his main interest in creating dynamic image of successive scenery, and his design usually had spatial energy expanding from private space to public space, and ultimately to infinite natural space. Methodologically, adding the plates of roof and floor was his main approach of design for emphasizing the mutual penetration of the interior and the exterior.

\subsection{Case Study}

-Bagsvaerd Church, Copenhagen, 1967-75, Jorn Utzon

The image of interior ceiling of this church was transferred from clouds of heavens for religious experience, and the feeling of change and ascent of its height induces dynamic psychology. The exterior is divided into earth and heavens, and heavens are more useful as an object of metaphor than earth in case of

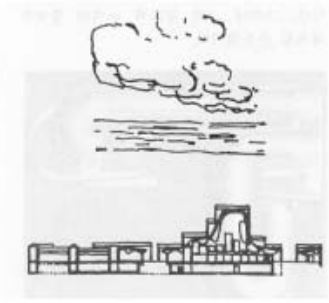

Fig. 9. Utzon's Image Sketch of Clouds religious architecture in which there needs to be much more movement of sublime spirit in proportion to unimportant material movement. Here clouds are symbolic presence which embodies the abstract presence of heavens far more concretely.

This church contrasts with Sydney Opera House of the same architect in that the exterior is humble compared to the interior's expressive elements in the church, while in Opera House the interior shows poor expressions of metaphor or analogy compared to the exterior's strong organic spirit.

The organic spirit of architecture in Jorn Utzon is expressed by extracting concepts not only from land of architecture but also based on situations of the program independently of the interior or the exterior, and, without any ostentation, it bestows abundant expression on the places in need of perspective emphasis of the architecture.

\section{Conclusion}

As this thesis has confirmed, there are two ways of figuring the ground: one is to transfer logically the exterior environment by analogy into the interior, and the other is the poetic attitude which encourages creativity by introducing contradictory space into the interior.

\begin{tabular}{|c|c|c|c|}
\hline & case & $\begin{array}{c}\text { mode of } \\
\text { interiorization }\end{array}$ & Results \\
\hline system & $\begin{array}{c}\text { Sendai } \\
\text { Mediatheque }\end{array}$ & $\begin{array}{l}\text { metaphor of water } \\
\text { plants }\end{array}$ & $\begin{array}{c}\text { abolition of boundary } \\
\text { between the interior } \\
\text { and exterior }\end{array}$ \\
\hline program & $\begin{array}{l}\text { Jussieu } \\
\text { Library }\end{array}$ & $\begin{array}{c}\text { indeterminate } \\
\text { program and ramp } \\
\text { transferred from } \\
\text { various programs } \\
\text { of city and } \\
\text { infrastructure }\end{array}$ & $\begin{array}{c}\text { Inducing various } \\
\text { human behaviors and } \\
\text { accommodating } \\
\text { congested culture by } \\
\text { introduction of event } \\
\text { space }\end{array}$ \\
\hline \multirow[t]{2}{*}{ image } & $\begin{array}{c}\text { Guggenheim } \\
\text { Museum }\end{array}$ & $\begin{array}{l}\text { analogy of } \\
\text { climbing a } \\
\text { mountain }\end{array}$ & $\begin{array}{c}\text { stressing dynamic and } \\
\text { successive scenery by } \\
\text { introduction of spiral } \\
\text { lamps }\end{array}$ \\
\hline & $\begin{array}{l}\text { Bagsvaerd } \\
\text { Church }\end{array}$ & $\begin{array}{l}\text { metaphor of } \\
\text { clouds }\end{array}$ & $\begin{array}{l}\text { embodiment of God, } \\
\text { the abstract existence }\end{array}$ \\
\hline
\end{tabular}

Table 3. Summary of Case Analysis

Main points of this thesis about introduction of elements of the external space can be summarized as follows.

First, the attitude of approach focused on system is metaphorical transference from energy of natural ecology, that is, substantial form of the exterior, and is 
expressed mainly by lightness and transparency. It is the maximum application of high technology of physics such as digital culture and high-tech architecture.

Second, the attitude of approach focused on program lays stress on the aspect of event transferred from various and free activities which are unpredictable in the exterior, and is usually made by the transformation of floor plate. In this attitude of approach, the introduction of elements of the exterior is emphasized.

Third, the attitude of approach focused on image appeals directly to aesthetic feeling mainly through intuitional expression of emotion by introducing the elements of prospect in the exterior. This concept is focused on the integration of the concepts of form, space, and place as the image in the human cognitive aspect.

\section{Acknowledgments}

This study was pursued with the support of Inha University's research fund in 2000.

\section{Notes}

Lee, Han-seok, An analysis on Analogical thinking in architectural design, Journal of the Architectural Institute of Korea, Planning \& Design Section, Vol. 13 No. 2, February 1997,p.40
2 The concept conceived by Arthur Koestler (1905 83) who criticizes the limit reductionism. Holon is a neological compound of holos and on which means part and whole at the same time.

3 Kwinter. S, Emergence: or the artificial life of space, Anywhere, Capress, 1998 , p. 214

4 Rhizome is a botanical term referring to a rootstock, that is, root is stalk, and it is the antithetical concept to western metaphysical traditions, which designates de-centered, multi-centered state.

5 Koolhaas, Rem. Two Libraries for Jussieu University, Paris . AA File. no 26. 1994 Autumn, p.37

\section{References}

1) Puglisi, L.P., Hyper architecture spaces in the electronic age, ezip, 2001

2) Yeo, Sang-hun, A study on the characteristics of Rhizome of Rem Koolhaas' urbanism and architecture, Master's thesis, Inha University, Korea, 2001

3) Lee, Han-seok, 'An analysis on Analogical thinking in architectural design,' Journal of the Architectural Institute of Korea Planning \& Design Section, Vol. 13 No. 2, February 1997

4) Koolhaas, Rem, Two Libraries for Jussieu University, Paris , AA File. no 26,1994 Autumn

5) Kim, Ki-soo, 'Sendai mediatheque of Toyo Ito,' Ideal architecture, January 2002, Seoul, Korea

6) Koolhaas, Rem, $S, M, L, X L, 101$ Publishers, 1995

7) Pfeiffer, B. Bruce, Frank Lloyd Wright Master Builder, New York: Rizzoli, 1997 